\title{
Secular trends in end-stage renal disease requiring dialysis in Manitoba, Canada: a population-based study
}

\author{
Paul Komenda MD MHA, Nancy Yu PhD, Stella Leung MSc, Keevin Bernstein MD, \\ James Blanchard PhD, Manish Sood MD, Claudio Rigatto MD MSc, Navdeep Tangri MD PhD
}

Abstract

Background: End-stage renal disease (ESRD) requiring dialysis is expensive and is associated with disproportionately poor health outcomes and quality of life. Understanding regional long-term secular trends in the incidence and prevalence of dialysis will allow for the alignment of appropriate and efficient delivery of care. The primary objective of this study was to describe long-term secular and geographic trends in ESRD over a 22-year period in a single-provider Canadian health care setting.

Methods: Using a previously validated case definition, we described the annual incidence and prevalence of ESRD in Manitoba from 1989 to 2010, stratified by age, sex and geographic location within the province.

Results: We searched more than 1.2 million records within the Manitoba Health repository. We identified 9489 patients in the Manitoba Health Physician Claims database with at least 1 claim for dialysis from 1989 through Mar. 31, 2010. Using the case definition of any 2 dialysis treatment claims, the total annual incidence of ESRD increased 2.5-fold from 15.8 to 40.2 per 100000 during the study period. Of note, the northern rural portions of the province saw a 12-fold unadjusted increase in ESRD, from 8.1 per 100000 in 1989 to 96.3 per 100000 in 2009.

Interpretation: The incidence and prevalence of ESRD is increasing in Manitoba, most notably in the north of the province. Innovative interventions, such as primary screening and treatment initiatives, should specially target northern rural regions.

$\mathrm{F}$ nd-stage renal disease (ESRD) requiring life-sustaining kidney replacement therapy is a global public health problem ${ }^{1}$ affecting more than 2 million people worldwide and more than 38000 Canadians. ${ }^{2,3}$ Manitoba has the highest incidence and prevalence of ESRD in Canada, partly because of its high burden of diabetes. ${ }^{2}$ This disease is associated with high morbidity and mortality, ${ }^{4}$ diminished quality of life $^{5}$ and disproportionately high costs to the health care system. ${ }^{6}$

Worldwide secular trends of the incidence and prevalence of ESRD are challenging to show because of variable population dynamics, the heterogeneous availability of dialysis services in certain countries and differences in the generalizability of dialysis registries., ${ }^{3,7}$ Countries with well-developed registries and broad availability of dialysis services, such as the United States and Canada, have reported a relative slowing of the incidence of ESRD during the last decade. ${ }^{2,8}$ In 2005, the Canadian Organ Replacement Register reported a peak incidence of 760 per million population for patients more than 75 years of age (the largest category), which steadily declined each year to 707 per million population in the last reported year (2008). ${ }^{2}$ There remains, however, considerable variability across regions within these countries with regards to incidence, prevalence and use of different types of dialysis. Canada is geographically broad with a large rural northern region and has unique challenges for health care delivery and disease surveillance. Unfortunately, few data exist regarding secular trends in the rate of ESRD by geographic region.

Many comprehensive databases and registries of dialysis providers in Canada are limited in their retrospective time horizon. A review of longitudinal administrative data remains an attractive option for analyzing secular trends in dialysis

Competing interests: Paul Komenda has received grant money from the Public Health Agency of Canada. No other competing interests were declared.

This article has been peer reviewed.

Correspondence to: Paul Komenda, paulkomenda@yahoo.com

CMAJ Open 2015. DOI:10.9778/cmajo.20130034 
growth. If accurate, these data will aid in the creation of surveillance and prevention programs that may be applied to more efficiently address the burden of ESRD. Thus, our primary objective was to examine the incidence, prevalence and geographic trends of ESRD in Manitoba over a 22-year period using novel and validated administrative case definitions. Our hope was that these long-term trends might provide novel insights into the way contemporary surveillance and prevention efforts should be targeted.

\section{Methods}

\section{Study population}

Manitoba, Canada, has a population of 1.2 million people. It is a central Canadian province with a universal payer health care system (Manitoba Health), which processes and maintains all claims for health care use in the province in a secured, centralized repository. ${ }^{9}$ Since 1984 , all residents of Manitoba have a unique personal health identification number that is attached to all health services claims submitted to Manitoba Health, who maintains digital records of these claims.

\section{Sources of data}

\section{Physician Claims Database}

Each physician claim includes the patient's identification number, the date of service and a 3-digit International Classification of Diseases, 9th revision, clinical modification (ICD-9-CM) code for the physician-assigned diagnosis. Each record of admission to hospital includes the patient's identification number, the dates of admission and discharge, and the diagnostic codes listed on the discharge abstract. Before 2004, up to 16 diagnoses were recorded using 5-digit ICD-9-CM codes; after 2004, up to 25 diagnoses were recording using codes from The Canadian Enhancement of the International Statistical Classification of Diseases and Related Health Problems, 10th revision (ICD-10-CA). In addition, Manitoba Health maintains a population registry that is updated when a person moves into or out of Manitoba, changes marital or family status, or dies.

To identify residents receiving dialysis in the Manitoba Health database, we searched all physician claims from Apr. 1, 1989, through Mar. 31, 2011, by tariff codes for initial dialysis (9798, 9801, 9805, 9806), subsequent dialysis (9799, 9802, 9807, 9819) and home dialysis (9821).

\section{Manitoba Renal Program Dialysis Registry}

The Manitoba Renal Program is the sole provider of dialysis and kidney health prevention services in the province. The program consists of more than 800 employees, including 23 actively practising nephrologists. The program has maintained a comprehensive database of all patients receiving chronic dialysis (> $90 \mathrm{~d}$ on dialysis), including start and end dates, in addition to detailed demographic and comorbidity data since January 2004. The quality of these data is adjudicated at formal interprofessional rounds on a weekly basis. The validation of this database has been described elsewhere, ${ }^{10}$ and the database has been used extensively in published epidemiologic studies.

\section{Administrative case definition for dialysis}

Based on previous validation studies that used administrative data to define ESRD, ${ }^{11}$ we chose at least 2 outpatient dialysis claims as the case definition for our study. We chose the study period of Jan. 1, 2004, to Dec. 31, 2010, based on the available, high-quality data from the Manitoba Renal Program for validation purposes. We will describe the detailed methods of validating administrative case definitions for chronic dialysis in a separate article in CMA7 Open. Briefly, we used the most accurate case definition based on the area under the receiver operating characteristic curve - any 2 dialysis treatment claims (86\% sensitivity, 93\% specificity). We allowed claims to be processed as many as 5 years after the reference year of interest to increase sensitivity and specificity.

\section{Incidence and prevalence}

To estimate the incidence of chronic dialysis, we examined longitudinal records of medical claims for all patients who met our administrative case definition. We considered the date of the first physician claim for a dialysis code to be the date of dialysis onset (incident case date). We calculated incidence rates from 1989 on to ensure the identification of new cases by using a 5-year washout period (1984-1988). People on dialysis who were alive in each subsequent year were counted as prevalent cases. Using the year of dialysis of incident and prevalent cases, we calculated the annual crude incidence and prevalence rates, adjusted for age and sex, using the mid-year population figures from the Manitoba Health population database. ${ }^{12}$ We calculated $95 \%$ confidence intervals (CIs) assuming a Poisson distribution, because new ESRD cases per year occur with some irregularity. Using patient postal codes, we reported home region of origin, dividing the province into 4 regions by approximate distance from Winnipeg (the largest tertiary care centre): north rural (distance $>300 \mathrm{~km})$, mid rural $(50-300 \mathrm{~km}$ north of Winnipeg), south rural (50-300 km south of Winnipeg) and urban (Winnipeg itself). We chose these geographic regions as surrogates for differential access to reliable, accessible primary and specialty care services mirrored by parameters such as population density and well-developed road access to communities. We performed all analyses using SAS version 9.

We analyzed trends over time using joined linear segments (Joinpoint version 4.1.0). ${ }^{13}$ Points at which linear segments join, known as points of inflection, represent changes in trends. We used regression analyses based on a Poisson distribution to determine the size of change (i.e., annual percentage change). We used the Monte Carlo method to determine models of best fit. We standardized age-adjusted analyses for secular trends to the cumulative Manitoba population from 1989 to 2010 . We set significance at $p$ less than 0.05 .

\section{Standard protocol approval, registration and patient consent}

This study received approval from the health research ethics boards of the University of Manitoba and the Winnipeg Regional Health Authority. We obtained Health Information 


\section{OPEN}

Privacy Committee approval from Manitoba Health, and data-sharing agreements were signed between these institutions. Patients provided individual consent for their data to be included in the Manitoba Renal Program database. We are not aware of any patients who have declined inclusion in this database.

\section{Results}

Using the administrative tariff codes for dialysis done by physicians, we identified 9489 patients in the Manitoba Health Physician Claims database with at least 1 record for dialysis from Apr. 1, 1989, through Mar. 31, 2011.

\section{Incidence and prevalence}

We applied our validated case definition of ESRD to the comprehensive administrative dataset from 1989 to 2011. The overall average annual incidence of ESRD in Manitoba over the course of the study was 18.7 cases per 100000 women (95\% CI 16.4 to 21.8) and 25.8 cases per 100000 men (95\% CI 23.6 to 26.4) (Table 1). Incidence rates increased with age. We found a slow increase in ageadjusted incidence of ESRD in Manitoba during the 22-year study period, which was accompanied by a more rapid increase in age-adjusted prevalence (Figure 1). In 1989, the provincial age-adjusted incidence of ESRD was 16.9 per 100000 , which increased to 37.8 per 100000 in 2010. During the same period, age-adjusted prevalence rose from 32.5 to 270.3 per 100000 - an 8 -fold increase. By the end of 2010, age-adjusted incidence and prevalence rates were higher in men than in women ( $3.0 \%$ v. $2.5 \%$ ).

\section{Prevalence by age}

The prevalence of ESRD increased in every age category during the study period (Figure 2). However, the overall increase in prevalence of ESRD toward the end of the study period was largely driven by patients between 55 and 85 years of age. Prevalence rates appear to be increasing with time, with rates increasing from 0.0005 in 1989 to 0.0068 in 2010 in the $75-84$ year age group.

\section{Incidence and prevalence by region}

In the north rural region of Manitoba, age-adjusted incidence of ESRD increased 4.5-fold (from 26.8 to 119.1 per 100 000, Figure 3), and unadjusted incidence increased 12 -fold, during the study period. Age-adjusted incidence of ESRD increased about 2.5 -fold in the urban, south rural and mid rural regions of the province between 1989 and 2008 (10.6 to 16.2 per 100000 v. 28.2 to 38.7 per 100 000, Figure 3). We saw similar results in prevalence rates, with 3 -fold higher prevalence in the north rural region compared with other regions (Figure 4), and an increase in prevalence in the north rural region of about 18-fold between 1989 and 2010.

\section{Trend analysis}

We found significant increases in the slope of each trend line over time for both incidence and prevalence of ESRD stratified by sex and region (Table 2).

\section{Interpretation}

Using a validated case definition for ESRD and data covering a period of 22 years, we found a disproportionate increase in the

Table 1: Average annual incidence of end-stage renal disease in Manitoba per 100000 population, by age and sex, $1989-2010$

\begin{tabular}{|c|c|c|c|c|c|c|c|c|}
\hline \multirow{3}{*}{$\begin{array}{l}\text { Age, yr } \\
0-24\end{array}$} & \multicolumn{3}{|c|}{ Women } & \multicolumn{3}{|c|}{ Men } & & \\
\hline & \multirow{2}{*}{$\begin{array}{c}\begin{array}{c}\text { No. of } \\
\text { cases }^{*}\end{array} \\
163\end{array}$} & \multicolumn{2}{|c|}{$\begin{array}{l}\text { Average annual incidence } \\
\qquad(95 \% \mathrm{Cl})\end{array}$} & \multirow{2}{*}{$\begin{array}{r}\begin{array}{c}\text { No. of } \\
\text { cases }^{*}\end{array} \\
179\end{array}$} & \multicolumn{2}{|c|}{$\begin{array}{l}\text { Average annual incidence } \\
\qquad(95 \% \mathrm{Cl})\end{array}$} & \multicolumn{2}{|c|}{ Rate ratio $(95 \% \mathrm{Cl})$} \\
\hline & & 2.9 & (2.5 to 3.4$)$ & & 3.0 & (2.6 to 3.5$)$ & 1.1 & (0.9 to 1.3$)$ \\
\hline $25-29$ & 74 & 6.2 & (4.9 to 7.8 ) & 94 & 7.8 & (6.4 to 9.6$)$ & 1.3 & (0.9 to 1.7$)$ \\
\hline $30-34$ & 112 & 9.3 & (7.7 to 11.2 ) & 119 & 9.8 & (8.2 to 11.8$)$ & 1.1 & (0.8 to 1.4$)$ \\
\hline $35-39$ & 111 & 9.3 & (7.7 to 11.2 ) & 183 & 15.2 & (13.1 to 17.6$)$ & 1.6 & (1.3 to 2.1$)$ \\
\hline $40-44$ & 166 & 14.5 & (12.4 to 16.8$)$ & 212 & 18.4 & (16.1 to 21.0 ) & 1.3 & (1.0 to 1.6$)$ \\
\hline $45-49$ & 209 & 19.8 & (17.3 to 22.7 ) & 306 & 28.9 & (25.8 to 32.3 ) & 1.5 & (1.2 to 1.7$)$ \\
\hline $50-54$ & 224 & 24.2 & (21.2 to 27.6 ) & 330 & 35.6 & (32.0 to 39.7 ) & 1.5 & (1.2 to 1.7$)$ \\
\hline $55-59$ & 322 & 39.7 & (35.6 to 44.3 ) & 430 & 53.9 & (49.1 to 59.3 ) & 1.4 & (1.2 to 1.6$)$ \\
\hline $60-64$ & 336 & 46.5 & (41.8 to 51.8 ) & 429 & 62.7 & (57.0 to 68.9 ) & 1.3 & (1.2 to 1.6$)$ \\
\hline $65-74$ & 704 & 57.5 & (53.4 to 61.9$)$ & 939 & 89.0 & (83.5 to 94.9$)$ & 1.5 & (1.4 to 1.7 ) \\
\hline $75-84$ & 515 & 59.1 & (54.2 to 64.4$)$ & 753 & 125.7 & (117.0 to 135.0 ) & 2.1 & (1.9 to 2.4 ) \\
\hline$\geq 85$ & 120 & 32.7 & (27.3 to 39.1 ) & 150 & 89.4 & (76.2 to 104.9 ) & 2.7 & (2.2 to 3.5 ) \\
\hline Total & 3056 & 18.7 & (16.4 to 21.8 ) & 4124 & 25.8 & (23.6 to 26.4 ) & 1.4 & (1.2 to 1.6 ) \\
\hline
\end{tabular}


incidence and prevalence of this disease in the north rural region of Manitoba. The provincial age-adjusted prevalence of ESRD has increased 8 -fold in 3 decades. These results suggest that despite a reported plateau in incidence and prevalence of ESRD in some parts of Canada, the population of patients with ESRD in Manitoba continues to increase. This increase is largely driven by older adult patients and those living in remote northern communities.

The leading cause of incident ESRD in Manitoba is type 2 diabetes $(>50 \%)$, and the most common cause of death is

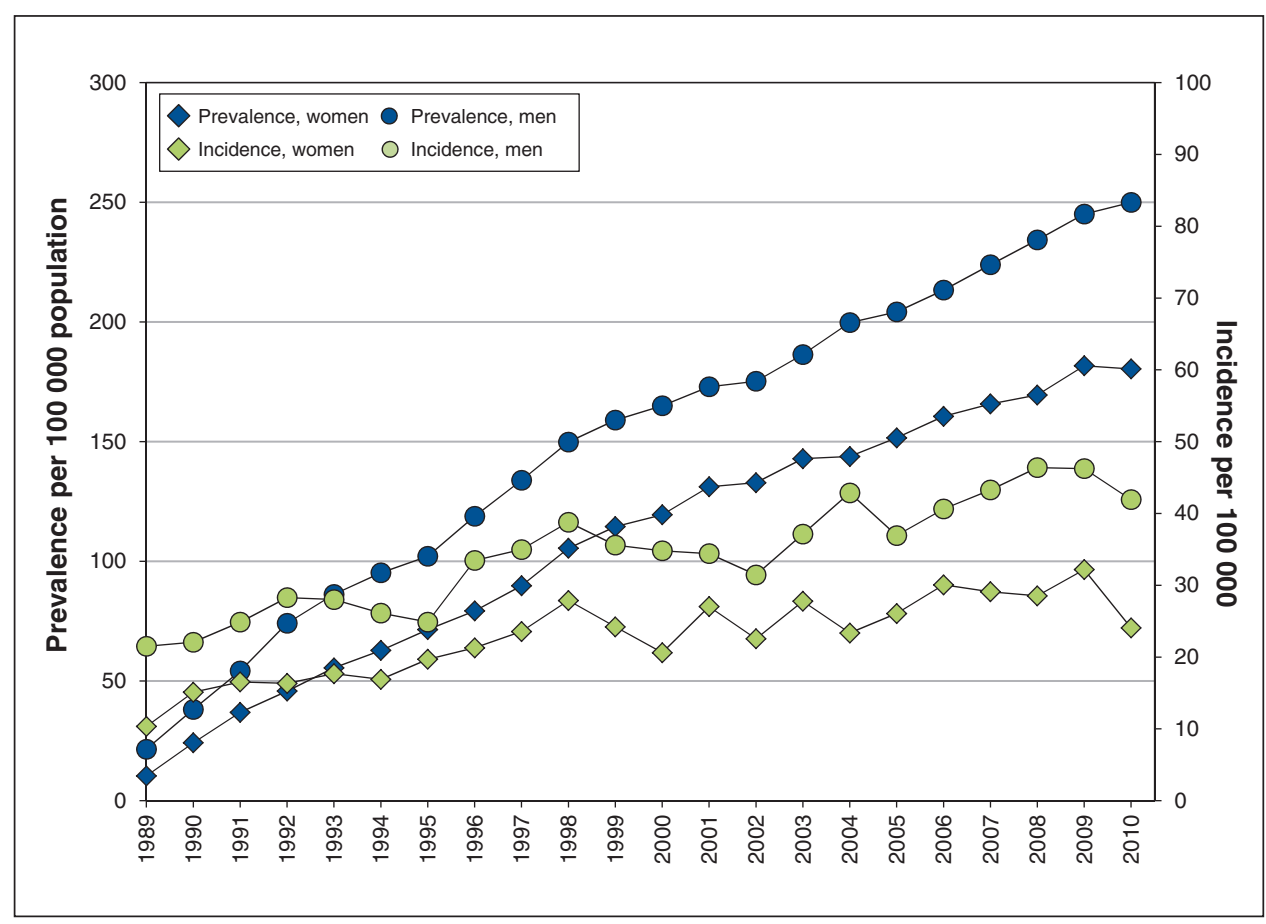

Figure 1: Age-standardized incidence and prevalence of end-stage renal disease in Manitoba per 100000 population, by sex, 1989-2010.

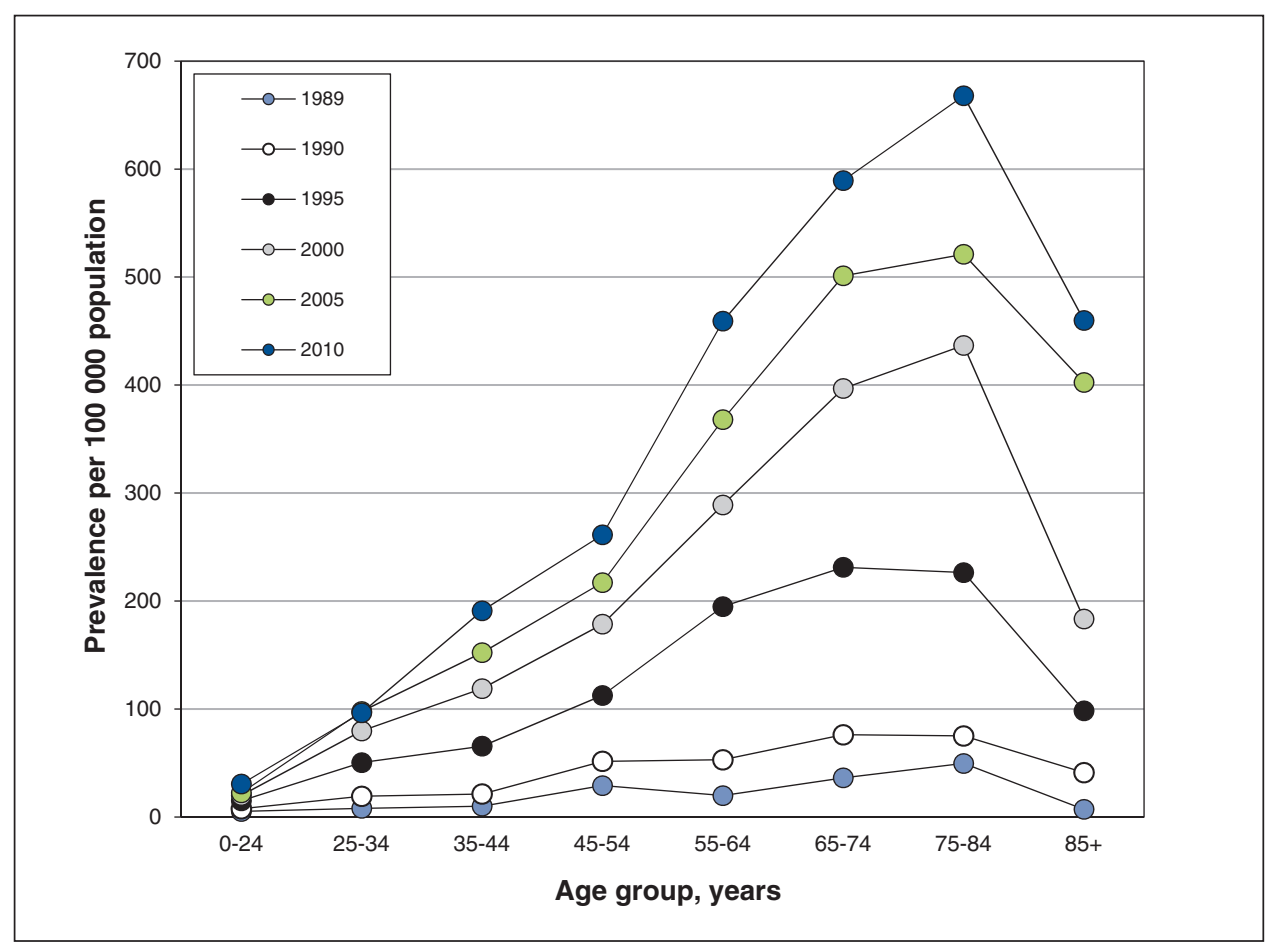

Figure 2: Age-specific prevalence of end-stage renal disease in Manitoba per 100000 population, by year, 1989-2010. 


\section{CMAJ OPEN}

\section{Research}

cardiovascular disease. ${ }^{14}$ The adjusted increase in the prevalence of ESRD is outpacing the increase in incidence, suggesting that at least some patients have improved survival, perhaps because of improved survival in cardiovascular disease and improved dialysis techniques (e.g., more frequent hemodialysis regimens and better infection-control practices). These results have substantial public health implications for policy-makers and health care providers. Innovative public health interventions in surveillance and early, riskbased prevention strategies are needed to attenuate this trend.

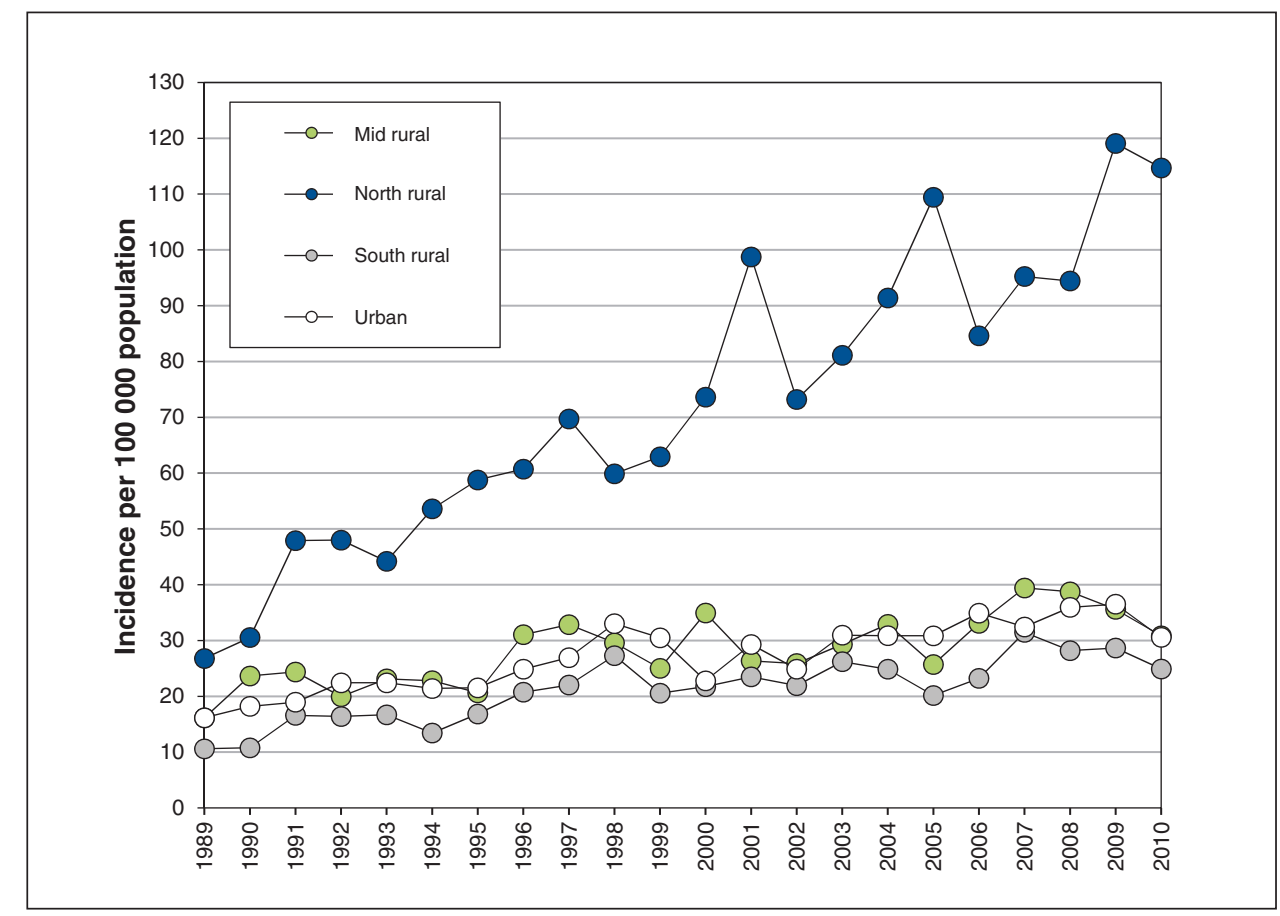

Figure 3: Age-standardized incidence of end-stage renal disease in Manitoba per 100000 population, by region, 1989-2010.

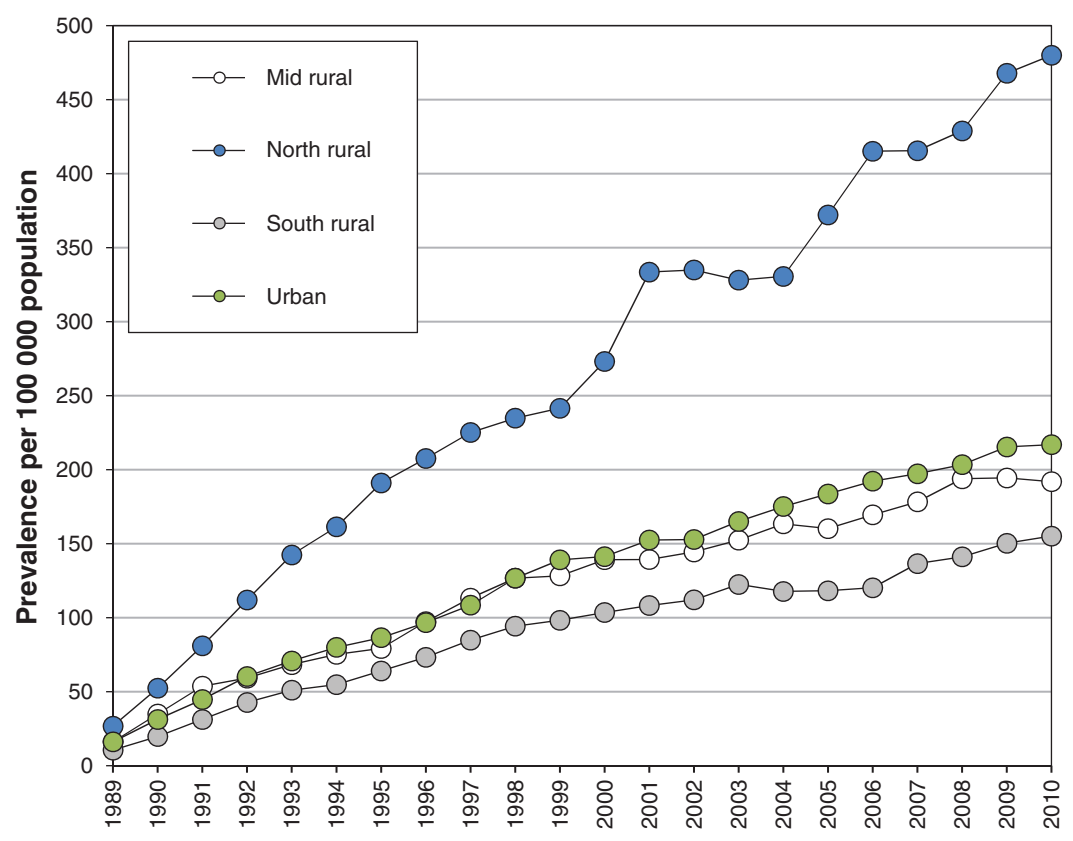

Figure 4: Age-standardized prevalence of end-stage renal disease in Manitoba per 100000 population, by region, 1989-2010. 
The increase in the age-adjusted rate of ESRD in northern Manitoba is noteworthy when one considers the trends seen in southern regions of Manitoba and the rest of Canada, where growth appears to be levelling off. Several factors may contribute to this epidemic of ESRD. Canada's North faces unique challenges related to its low population density, with many isolated communities having limited access to health care resources. ${ }^{15}$ In addition, patients in remote and rural regions of northern Manitoba are more likely to be of Aboriginal descent and to have socio-demographic characteristics associated with poor health outcomes, such as poverty, unemployment and lower levels of formal education than their urban counterparts. ${ }^{15-17}$ Aboriginal Canadians have a 2- to 3-fold higher prevalence of ESRD, ${ }^{18}$ are more likely to start hemodialysis and are much less likely to receive a kidney transplant than non-Aboriginal Canadians. ${ }^{19}$ In addition, Canada's North has a higher burden of other chronic diseases, such as cardiovascular and respiratory diseases (e.g., tuberculosis) and certain types of cancer (notably cervical, breast, melanoma and prostate), as well as shorter life expectancy for its inhabitants. ${ }^{17,20,21}$ These phenomena are not unique to Canada; a higher incidence of ESRD attributed to diabetes has been described in the United States in rural populations with poor access to primary care. ${ }^{18}$
The combination of demography, geography and climate all potentially contribute to the high rate of chronic kidney disease and ESRD, although there is likely a strong modifying effect of low socio-economic status on the increased incidence of preventable ESRD. ${ }^{21}$

Another explanation for this trend could be the increased availability of satellite hemodialysis or home dialysis modalities (peritoneal or home hemodialysis) in some of Manitoba's northern communities. Some patients who would have otherwise needed to relocate to Winnipeg to receive hemodialysis or choose a palliative approach to treating ESRD may now be opting for referral to nephrology and dialysis closer to home. With improved, safer dialysis care closer to or in the home (including the purported benefits of more frequent intensive home hemodialysis regimens), patients in remote communities may now be living longer with ESRD. However, administrative data alone are insufficient to test this hypothesis.

The Canadian Organ Replacement Registry has reported on the changing demographics of ESRD incidence and prevalence since 2001, and Manitoba consistently has the highest incidence and prevalence of ESRD and the highest use of dialysis in Canada. ${ }^{2}$ Thus, Manitoba has a vested interest in examining detailed epidemiologic trends in ESRD to tailor

Table 2: Trend analysis of end-stage renal disease over time, by sex and health region

\begin{tabular}{|c|c|c|c|c|c|c|c|c|}
\hline \multirow[b]{2}{*}{ Variable } & \multicolumn{4}{|c|}{ Incidence } & \multicolumn{4}{|c|}{ Prevalence } \\
\hline & \multirow[t]{2}{*}{$\begin{array}{l}\text { No. of inflection } \\
\text { points }\end{array}$} & \multirow[t]{2}{*}{ Period } & \multicolumn{2}{|c|}{$\begin{array}{l}\text { Annual percentage change* } \\
\qquad(95 \% \mathrm{Cl})\end{array}$} & \multirow[t]{2}{*}{$\begin{array}{l}\text { No. of inflection } \\
\text { points }\end{array}$} & \multirow[t]{2}{*}{ Period } & \multicolumn{2}{|c|}{$\begin{array}{l}\text { Annual percentage change } \\
(95 \% \mathrm{Cl})\end{array}$} \\
\hline \multicolumn{5}{|l|}{ Sex } & & & & \\
\hline \multirow[t]{3}{*}{ Female } & 1 & 1989-1998 & 7.3 & $(3.7 \text { to } 11.1)^{*}$ & 2 & 1989-1991 & 87.5 & (53.1 to 129.6 ) \\
\hline & & 1998-2010 & 1.3 & $(-0.4$ to 3.1$)$ & & 1991-1999 & 14.2 & $(12.8 \text { to } 15.5)^{\star}$ \\
\hline & & & & & & 1999-2010 & 4.2 & $(3.8 \text { to } 4.6)^{\star}$ \\
\hline \multirow[t]{3}{*}{ Male } & 0 & 1989-2010 & 3.2 & $(2.5 \text { to } 3.9)^{*}$ & 2 & 1989-1992 & 45.8 & $(36.6 \text { to } 55.5)^{*}$ \\
\hline & & & & & & 1992-1998 & 12.2 & $(10.5 \text { to } 13.9)^{*}$ \\
\hline & & & & & & 1998-2010 & 4.5 & $(4.2 \text { to } 4.8)^{*}$ \\
\hline \multicolumn{9}{|c|}{ Health region } \\
\hline \multirow[t]{3}{*}{ Mid rural } & 0 & 1989-2010 & 2.6 & $(1.5 \text { to } 3.6)^{*}$ & 2 & $1989-1991$ & 69.6 & $(31.7 \text { to } 118.4)^{*}$ \\
\hline & & & & & & $1991-1998$ & 13.2 & $(10.8 \text { to } 15.7)^{*}$ \\
\hline & & & & & & 1998-2010 & 4.0 & $(3.4 \text { to } 4.5)^{*}$ \\
\hline \multirow[t]{3}{*}{ North rural } & 0 & 1989-2010 & 5.5 & $(4.4 \text { to } 6.5)^{\star}$ & 2 & 1989-1993 & 45.0 & $(31.1 \text { to } 60.4)^{*}$ \\
\hline & & & & & & $1993-2001$ & 9.0 & $(6.8 \text { to } 11.4)^{*}$ \\
\hline & & & & & & $2001-2010$ & 5.1 & $(4.1 \text { to } 6.1)^{*}$ \\
\hline \multirow[t]{3}{*}{ South rural } & 0 & 1989-2010 & 3.4 & $(2.3 \text { to } 4.6)^{*}$ & 2 & 1989-1992 & 53.1 & $(31.9 \text { to } 77.7)^{\star}$ \\
\hline & & & & & & 1992-1998 & 13.6 & $(9.9 \text { to } 17.4)^{*}$ \\
\hline & & & & & & 1998-2010 & 4.0 & $(3.4 \text { to } 4.7)^{\star}$ \\
\hline \multirow[t]{3}{*}{ Urban } & 0 & 1989-2010 & 3.0 & $(2.2 \text { to } 3.9)^{*}$ & 2 & 1989-1992 & 48.1 & $(34.3 \text { to } 63.3)^{*}$ \\
\hline & & & & & & 1992-1999 & 12.0 & $(10.2 \text { to } 13.9)^{*}$ \\
\hline & & & & & & 1999-2010 & 4.4 & $(3.9 \text { to } 4.9)^{*}$ \\
\hline
\end{tabular}


surveillance and prevention efforts and to forecast demand for optimal resource allocation.

Our results have several clinical, research and policy implications. First, they suggest that screening for diabetes, hypertension and kidney disease, as well as treatment for the prevention of kidney failure in patients with established chronic kidney disease, should be preferentially targeted in rural and remote northern regions. Although providing health services in these regions is challenging, the payoff is likely to be large. Second, research is needed to more accurately identify the biological determinants of a poor renal prognosis for patients who live in these communities. Engagement of the Aboriginal community in this effort is critical for success. Finally, we believe that kidney disease and its prevention and treatment should be considered a strategic priority in health care funding for Aboriginal communities, and that present and future funding initiatives should be critically evaluated for their efficacy in reducing the incidence of kidney failure.

\section{Limitations}

The Manitoba Renal Program database is maintained and adjudicated for outcomes on a weekly basis, but there is a possibility of patients being omitted from the registry. We expect that this number is small.

Our determination of patient region was by postal code derived from the Manitoba Health repository. However, this listing may not always be the actual location of a patient's residence and may not account for patient migration for work or other reasons. In addition, we did not explore our analysis within the northern region of Manitoba stratified by specific community, road access or proximity to a satellite hemodialysis facility because of the limitations in collecting this level of data using only postal codes.

We did not distinguish between peritoneal or hemodialysis regimens because of the difficulty in tracking changes in modality using administrative data. However, the crude rate of peritoneal dialysis has fluctuated by only about $2 \%-4 \%$ per year, and overall home hemodialysis use remained small during the study period, increasing only after 2010 .

\section{Conclusion and implications for future research}

Urgent attention is needed to support well-developed primary surveillance and prevention initiatives in rural and remote locations where increases in the use of dialysis are disproportionately high. Despite the availability of well-developed reporting systems in Canada, such as the Canadian Organ Replacement Register, there is additional value in examining long-term secular trends in dialysis derived from validated administrative case definitions of ESRD to explain regional variations in incidence and prevalence. Our case definitions are readily transferable to other jurisdictions where longitudinal administrative data are available.

Further study is needed to examine the cost of investing in primary surveillance and prevention initiatives as opposed to the construction of dialysis facilities in locations with low population density.

\section{References}

1. Levey AS, Atkins R, Coresh J, et al. Chronic kidney disease as a global public health problem: approaches and initiatives - a position statement from kidney disease improving global outcomes. Kidney Int 2007;72:247-59.

2. Canadian Institute for Health Information (CIHI). Canadian Organ Replacement Register annual report: treatment of end stage organ failure in Canada, 2001 to 2010. Ottawa: CIHI; 2012.

3. Eggers PW. Has the incidence of end-stage renal disease in the USA and other countries stabilized? Curr Opin Nephrol Hypertens 2011;20:241-5.

4. Kucirka LM, Grams ME, Lessler J, et al. Association of race and age with survival among patients undergoing dialysis. 7AMA 2011;306:620-6.

5. Osthus TB, von der Lippe N, Ribu L, et al. Health-related quality of life and all-cause mortality in patients with diabetes on dialysis. BMC Nephrol 2012;13:78.

6. McFarlane P, Komenda P. Economic considerations in frequent home hemodialysis. Semin Dial 2011;24:678-83.

7. Eggers PW. The aging pandemic: demographic changes in the general and end-stage renal disease populations. Semin Nephrol 2009;29:551-4.

8. United States Renal Data System. USRDS 2011 Annual Data Report: Atlas of chronic kidney disease and end-stage renal disease in the United States, National Institutes of Health, National Institute of Diabetes and Digestive and Kidney Diseases, Bethesda, MD, 2011. Bethesda (MD): USRDS; 2011.

9. Manitoba Health and Healthy Living Report, Fune 1, 2008. Winnipeg: Health Information Management Branch; 2008.

10. Sood MM, Komenda P, Sood AR, et al. Adverse outcomes among Aboriginal patients receiving peritoneal dialysis. CMA7 2010;182:1433-9.

11. Clement FM, James MT, Chin R, et al. Validation of a case definition to define chronic dialysis using outpatient administrative data. BMC Med Res Metbodol 2011;11:25.

12. Rothmanm, KJ, Grennland, S. Modern epidemiology. 2nd ed. Philadelphia (PA): Lippincott, Williams and Williams; 1998.

13. Kim HJ, Fay MP, Feuer EJ, et al. Permutation tests for joinpoint regression with applications to cancer rates [published erratum in Stat Med 2001;20:655]. Stat Med 2000;19:335-51.

14. Canadian Institute for Health Information. Treatment of end-stage organ failure in Canada, 2002-2011. Ottawa: Canadian Institute for Health Information; 2013. Available https://secure.cihi.ca/estore/productFamily.htm?locale=en\&pf =PFC2053\&lang=en (accessed 2014 Oct. 16).

15. How bealthy are rural Canadians? An assessment of their health status and bealth determinants. Summary report. Ottawa: Canadian Institute for Health Information; 2006.

16. Liu JJ. Health professional shortage and health status and health care access. 7 Health Care Poor Underserved 2007;18:590-8.

17. Thomlinson E, McDonagh MK, Baird Crooks K, et al. Health beliefs of rural Canadians: implications for practice. Aust 7 Rural Health 2004:12:258-63.

18. Dyck R, Osgood N, Lin T, et al. End stage renal disease among people with diabetes: a comparison of First Nations people and other Saskatchewan residents from 1981 to 2005. Can 7 Diabetes. 2010;34:324-33.

19. Hemmelgarn BR. Canadian Society for Clinical Investigation Joe Doupe lecture: End stage renal disease among Aboriginal people. Clin Invest Med 2006;29:383-7.

20. Pampalon R, Martinez J, Hamel D. Does living in rural areas make a difference for health in Québec? Health Place 2006;12:421-35.

21. Smith KB, Humphreys JS, Wilson MGA. Addressing the health disadvantage of rural populations: How does epidemiological evidence inform rural health policies and research? Aust 7 Rural Health 2008;16:56-66.

Affiliations: Section of Nephrology, Department of Medicine (Komenda, Bernstein, Sood, Rigatto, Tangri), University of Manitoba, Winnipeg, Man.; Seven Oaks General Hospital (Komenda, Blanchard, Rigatto, Tangri), Winnipeg, Man.; Department of Community Health Sciences (Yu, Leung, Tangri), University of Manitoba, Winnipeg, Man.; Health Sciences Centre (Bernstein), Winnipeg, Man.; Ottawa Hospital Research Institute (Sood), University of Ottawa, Ottawa, Ont.

Contributors: Navdeep Tangri and Paul Komenda contributed to the conception and design of the study and drafted the manuscript. All of the authors contributed to the interpretation and analysis of the data and the revision of the manuscript for important intellectual content. All of the authors approved the final version of the manuscript submitted for publication and agree to act as guarantors of the work.

Acknowledgement: The authors thank Christine Bencharski for her assistance in formatting and submitting the manuscript.

Supplemental information: For reviewer comments and the original submission of this manuscript, please see www.cmajopen.ca/content/3/1 /E8/suppl/DC1 